\title{
Water, Air, and Soil Pollution
}

\author{
Jack Trevors
}

Published online: 2 December 2009

(C) Springer Science + Business Media B.V. 2009

\section{Preface}

This collection of 50 editorials reflects on present and future pollution challenges and humanitarian priorities in our common, shared biosphere. The two priority challenges are human population and excess resource consumption control. These can be considered to be responsible for global climate change and the tremendously high levels of pollution that threaten the biosphere. Solutions to these challenges are presented that must be implemented by individuals, communities, nations, and international communities. The tasks ahead are immense as these solutions must be implemented in the face of a multitude of problems, such as conflicts, lack of leadership, economic corruption, discrimination, unstable governments, dictatorships, pandemics, lack of infrastructure, an insufficiency of education and public health, poverty, and over one billion humans without the basic needs of life being met. It is hoped these editorials will be of value to all of humanity as we try to solve our most pressing problems.

The expert assistance, insight and wisdom of coauthor Professor Milton Saier in preparing numerous editorials is sincerely appreciated. Sincere appreciation is also extended to Dr. Paul Roos and Betty van Herk of the Springer management team.

J. Trevors $(\bowtie)$

School of Environmental Sciences, University of Guelph, Rm 3220 Bovey Bldg, Guelph, ON N1G 2W1, Canada

e-mail: jtrevors@uoguelph.ca 